\title{
Tobacco in Adolescence: Importance to Knowledge the Health Hazards and Preventive Measures
}

André Luís Bertani*, Thaís Garcia, Suzana Erico Tanni and Irma Godoy

Department of Internal Medicine, Botucatu Medical School, Unesp - Univ. Estadual Paulista, Botucatu Campus, Pneumology Area, Brazil

*Corresponding author: André Luís Bertani, Department of Internal Medicine, Botucatu Medical School, Unesp - Univ. Estadual Paulista, Botucatu Campus, Pneumology Area, Distrito de Rubião Junior, Botucatu, Sao Paulo, Brazil, 18618-000, Tel: 0055143880117, Fax: 00551438822238; Email: andrelubert@gmail.com

Received date: Feb 25, 2015; Accepted date: Mar 27, 2015; Published date: Mar 31, 2015

Copyright: (c) 2015 André Luís Bertani, et al. This is an open-access article distributed under the terms of the Creative Commons Attribution License, which permits unrestricted use, distribution, and reproduction in any medium, provided the original author and source are credited.

\section{Abstract}

Objective: To contribute to the development of prevention tools by identifying the pattern of tobacco use, knowledge about tobacco-related diseases and media tools that are popular among adolescents.

Material and Method: In a cross-sectional study, sixty adolescents $(41.7 \%$ smokers, $28.3 \%$ ex-smokers and $30 \%$ never smokers) attending the secondary level of a public school (Botucatu, São Paulo, Brazil) were interviewed using a standardized questionnaire. The Hospital Anxiety and Depression Scale (HADS) was applied to all subjects. The Fagerström score and motivation to give up smoking (Prochaska e DiClemente) were evaluated in smokers.

Results: The mean age was $15.8 \pm 1.1$ years old, and $65 \%$ were female. Among the smokers, $60 \%$ were girls and among ex-smokers, 59\%. A high proportion of smokers and ex-smokers had used alternative forms of tobacco such as narghile (52.4\%) and flavored cigarettes (54.8\%). A very low proportion of the adolescents associated smoking with cardiovascular disease $(1.7 \%)$, neurological problems $(1.7 \%)$, heart disease $(5 \%)$, dental problems $(5 \%)$, skin aging (5\%) and even cancer (36.7\%). The majority of smokers $(96 \%)$ and ex-smokers $(88.2 \%)$ had low nicotine dependence, $76.1 \%$ of them did not consider themselves addicted to nicotine and stated that they could stop whenever they wanted. Internet accessed by computer was the favorite media tool for $58.3 \%$ of the adolescents.

Conclusions: Use of alternative forms of smoking is high, and the knowledge about the consequences of any tobacco consumption is very poor and sometimes misleading among adolescents. Our data indicate that personalized internet tools should be developed to gain the interest of adolescents in smoking prevention and cessation.

Keywords: Adolescents; Knowledge; Smoking cessation; Tobacco products; Internet; Primary prevention

\section{Introduction}

Smoking is a learned behaviour in children and adolescents, influenced by parents, family members, peers and by a large range of other individual, social and political factors [1]. Adolescents from lowincome families and those living with divorced parents have relatively high risk of becoming regular smokers [2]. The influence of peers is a particularly strong factor for smoking initiation in adolescents, and parents or family members who smoke tobacco also present a very important influence on smoking initiation in children [3-7].

In 2012, a systematic review of existing studies that evaluated Brazilian adolescents reported smoking prevalence in the range of $2.4 \%$ to $22 \%$. On average, the prevalence was approximately $10 \%$; however, in $20 \%$ of the investigations, it was higher than $15 \%$ [8]. In the studies that presented results stratified according to sex, 55\% showed higher prevalence in females for various patterns of cigarette consumption [8].

The tobacco industry uses additives to camouflage the odor and taste of nicotine, to enhance or maintain nicotine delivery and to increase the addictiveness of cigarettes. The industry also employs marketing strategies that could increase the appeal of smoking for children and adolescents [9]. In addition, much of the tobacco use and addiction of youth is maintained by means others than cigarettes, such as narghile, which has a higher concentration of nicotine than industrialized cigarettes and is also associated with many of the known risks related to tobacco smoking [10].

National and international guidelines for smoking cessation identify adolescents as a special population that requires tailored interventions [3,11,12]. However, few Brazilian studies have evaluated the knowledge about tobacco smoking among adolescents [13-16], and none have evaluated the technology preferences of this age group to design tailored interventions. Therefore, the main objective of the present study was to identify the pattern of tobacco use, knowledge about tobacco-related diseases and media tools popular among adolescents to contribute to the development of prevention and cessation tools.

\section{Materials and Methods}

\section{Subjects}

Sixty adolescents (41.7\% smokers, $28.3 \%$ ex-smokers, $30 \%$ never smokers) were selected among those attending the secondary level of a 
public school in Botucatu, São Paulo, Brazil. The study was approved by the Research Ethics Committee of Botucatu Medical School University Hospital, and all students, or the legally responsible guardians of students younger than $18 \mathrm{yr}$, signed an informed consent.

\section{Study design and procedures}

This was a descriptive cross-sectional study interviewing adolescents attending the secondary level of a public school in Botucatu between January-July 2012. The only exclusion criteria would be the refusal to participate and all invited adolescents randomly accept to answer the questionnaires. The investigator approached the students in the classroom and explained the aims of the study. The interviews were face to face with the investigator using a questionnaire developed for the study. The students freely answered questions about active and passive smoking, smoking habits between peers and during social activities, family history of tobacco-related diseases and knowledge about tobacco dependence and adverse health consequences. In addition, all the students answered questions from the Hospital Anxiety and Depression Scale (HADS) [17], and the smokers and ex-smokers were administered the Fagerström test for nicotine dependence [18] and Prochaska and DiClemente motivational stage [19].

\section{Statistical analyses}

We used the chi-square test for comparison of proportions and ANOVA and Tukey tests to compare means. Both evaluations were performed with $80 \%$ power and an established significance level of $5 \%$.

\section{Results}

The main characteristics of the sample are presented in Table 1. There was predominance of female sex, a high proportion of current or occasional smokers (41.7\%) and of passive smoking. Age of smoking initiation was between 14 and $16 \mathrm{yr}$ in $73.8 \%$ and between 10 and $13 \mathrm{yr}$ in $26.2 \%$. In regard to factors associated with smoking initiation, $71.4 \%$ were related to the influence of peers and $9.5 \%$ were associated with the smoking habits of the parents of the smoking adolescent. Among adolescents who had a best friend smoking, the proportions of smokers and ex-smokers were higher than the proportion of never smokers $(63.2 \%$ vs $26.3 \%$ and $10.5 \%, \mathrm{p}=0.020)$. Facilitation of social relationships was mentioned by $59.5 \%$ as a cause to not give up smoking. Almost $50 \%$ of the adolescents practiced some physical activity, mostly in groups (71.4\%), and all who had smoking partners during these activities were also smokers $(\mathrm{p}=0.001)$.

\begin{tabular}{|l|l|}
\hline Variables & $\mathbf{N}=\mathbf{6 0}$ \\
\hline Age $(\mathrm{y})$ & $15.8 \pm 1.1$ \\
\hline Sex (male/female) \% & $35 / 65$ \\
\hline Smokers (regular/occasional) \% & $21.7 / 20.0$ \\
\hline Ex-smokers (\%) & 28.3 \\
\hline Passive smokers (family/social groups)\% & $55 / 75$ \\
\hline
\end{tabular}

Table 1: Characteristics of the student participants.

Some adolescents (13.3\%) reportedly believe that cigarette smokers do not develop dependence to nicotine, as other illegal drugs users, or that if dependence is present, it is only psychological. Most smokers
(96\%) and ex-smokers (88.2\%) had a low degree of dependence to nicotine according to the Fagerström test [18] and $76.1 \%$ did not consider themselves nicotine dependent. Most smokers (76\%) were contemplative about smoking cessation and also believed that they could stop smoking at any time.

Narghile is very popular among adolescents (Figure 1). A higher proportion of smokers than ex-smokers reported previous experience with narghile $(70.6 \%$ vs $29.4 \%, \mathrm{p}=0.002)$, pipe or cigar $(83.3 \%$ vs $16.7 \%, \mathrm{p}=0.004)$ or flavored cigarettes $(71.9 \%$ vs $28.1 \%, \mathrm{p}=0.001)$. A small proportion of smokers and ex-smokers (7\%) smoked only narghile before the initiation of using industrialized cigarettes. Most became acquainted with narghile through friends and relatives (70.4\%), and $22.2 \%$ reported peers who smoke narghile inside the school. In addition, 16(6\%) of the adolescents reported that narghile and marijuana have no adverse health consequences.

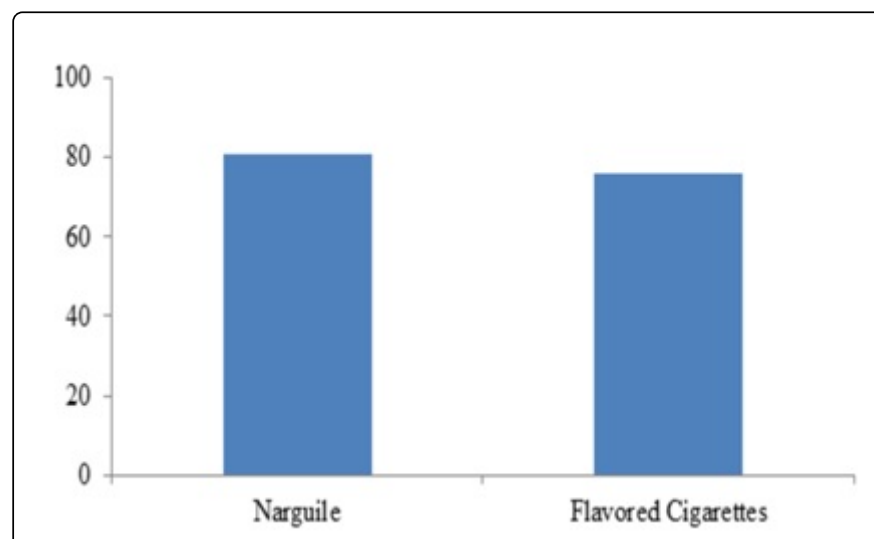

Figure 1: Proportion (\%) of adolescents who know narghile and flavoured cigarettes.

Knowledge about health consequences of smoking in long-term users was very low (Figure 2).

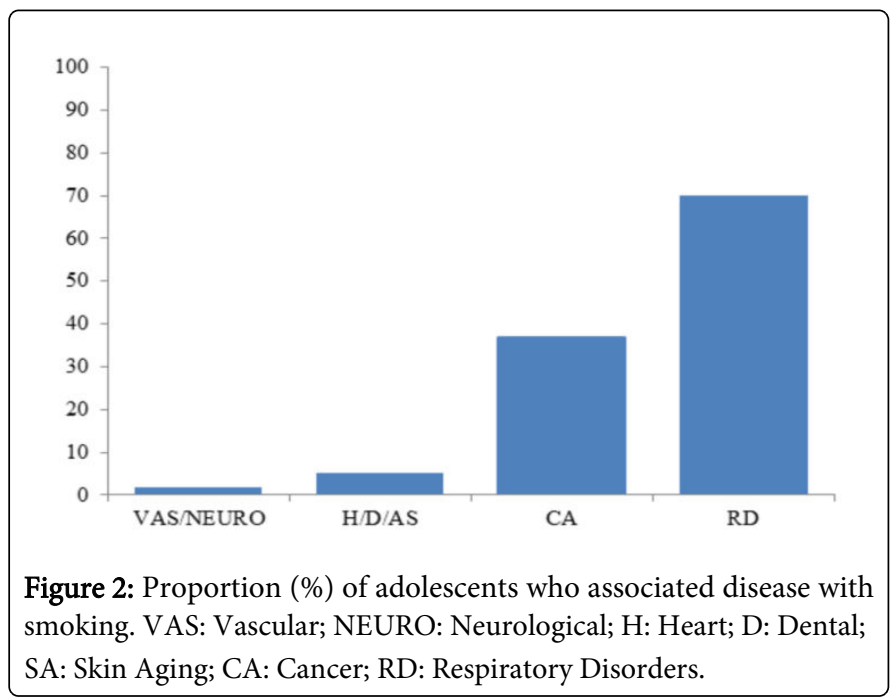

Less than $5 \%$ knew that tobacco is related to dermatological, dental, neurological and cardiovascular diseases. An association with cancer was identified by only $36.7 \%$ and respiratory problems by $70 \%$ of the adolescents. In addition, some relate cigarette smoking with good feelings and pleasure (13.3\%) and/or calming influence (6.7\%). Passive 
smoking was associated with respiratory problems by only $8.3 \%$ of the adolescents and, although $35 \%$ reported to know that there are health consequences to passive exposure to smoke, they were not able to name them. Furthermore, 3.3\% believe that passive exposure to smoke did not cause health problems. When asked about the importance of education related to tobacco health consequences, $55 \%$ agree that additional knowledge may motivate smoking cessation and $80 \%$ expressed an interest in acquiring more information.

The proportion of adolescent smokers presenting dyspnea was higher than that of ex-smokers ( $62.5 \mathrm{vs} 12.5 \%, \mathrm{p}=0.008)$, and the same was true for dizziness $(56.2 \%$ vs $12.5 \%, \mathrm{p}=0.003)$ and tachycardia $(85.7$ vs $14.3 \%)$. According to the HAD scale, $25 \%$ presented scores compatible with a high probability of anxiety, while only $1.7 \%$ presented scores compatible with depression. Some adolescents $(20 \%)$ reported symptoms of asthma, and 5\% were currently being treated for hypertension. The prevalence of tobacco-related disease in relatives was frequent; $26.6 \%$ mentioned chronic obstructive pulmonary disease and $26.6 \%$ cardiovascular diseases among their relatives.

We also investigated which electronic media device was preferred by the adolescents; $63.3 \%$ use traditional television, and $88.3 \%$ access the internet by desktop computer and $48.3 \%$ by cell phone. Internet by desktop is the electronic device most utilized for entertainment $(58.3 \%)$.

\section{Discussion}

The primary findings of the present study were a high prevalence of current smokers and passive exposure to tobacco smoke, abundant misconceptions about nicotine dependence despite the widespread information available and that narghile and flavored cigarettes are very popular among adolescents. However, knowledge about the health consequences of traditional or alternatives forms of tobacco smoke is lacking. The internet appears to be the most appropriate media tool to be utilized for the development of educational material for this age group.

The prevalence of current smokers among adolescents has been stable in recent years in Brazil. Previous studies have shown a prevalence of $20.7 \%$ in 1998 [20], 22\% in 2004 [1] and $21 \%$ in 2009 [21]. These data are in agreement with the prevalence found in the present study (21.7\%). This is in contrast with the decrease of $20 \%$ in the national smoking prevalence in Brazil between 2006 and 2012 in individual solder than $18 \mathrm{yr}$ [22]. We found a higher proportion of females among the adolescent smokers, similar to a 2009 study performed in Brazil (girls: 53\% vs. boys: 47\%) [23] and in contrast with other previous studies that showed a higher prevalence in boys $[24,25]$. These data reinforce the recent increasing trend of tobacco smoking among girls [8].

The adolescents reported a high passive exposure to tobacco smoke at home (55\%) and with peers (75\%), even inside of school (13\%) and during social activities (87\%). The Report on The Global Tobacco Epidemic showed that $41 \%$ of the children and adolescents in the USA and $78 \%$ in Europe were exposed to tobacco smoke [26]. A recent study performed in Brazil showed that the prevalence of passive exposure to smoking was $29 \%$ at home and $68 \%$ in the school environment, data which are in agreement with the findings of our study [27].

The reported awareness of adolescents in the present study in relation to active smoking and the consequential harms to health was very low despite the massive amount of information available. These findings are consistent with several studies $[13,14,16]$ that showed that among various cancers that are related to smoking, teens associated only lung cancer with smoking [13]. Respiratory, cardiac and dental problems were mentioned by adolescents in a nonspecific manner $[13,14,16]$. Several students related cigarette use with some benefit, which clearly indicates the ambivalence of adolescents toward this issue and may explain, at least partially, the lack of motivation for smoking cessation.

In the present study, the majority of smokers (96\%) and ex-smokers (88.2\%) had low nicotine dependence (score of less than 5 on the Fagerström test [18]). Although $80 \%$ of adolescents believed that smoking leads to nicotine dependence, $76.1 \%$ of them did not consider themselves addicted to nicotine and stated that they were capable of quitting smoking at any time. The degree of nicotine dependence and personal views of teenagers about addiction caused by tobacco use have been addressed by several previous studies $[13,15,16]$. Lopes and colleagues showed that adolescents consider drug addiction as a disease caused by smoking [13]. However, in other studies that assessed the opinions on nicotine dependence and harm of smoking to health, the teens surveyed reported that smoking does not cause as many consequences as do illicit drugs [15], and adolescent smokers said they could quit if they wanted to [16]. Regarding the degree of nicotine dependence assessed by the Fagerström scale [18], Almeida and Mussi showed low scores related to the degree of dependence in 91\% of adolescent smokers [16]. As expected, the onset of smoking, which occurs predominantly in adolescence, is seen as a controllable behavior by individuals in this stage of life and does not appear to be perceived as a high hazard for tobacco-related diseases because less than half of the ex-smokers ceased smoking for that reason.

A report by Vigescola in 2009 showed that $22.1 \%$ of the adolescents interviewed in the city of São Paulo were using alternative forms of tobacco, and $93.3 \%$ had a preference for narghile [28]. Research conducted in the United States showed that $75 \%$ of users of narghile believe that the use of this alternative form of tobacco causes a lesser amount of harm to health than do conventional cigarettes [29]. According to the Centers for Disease Control and Prevention in 2012, the consumption of conventional cigarettes among youth declined by $1 \%$ compared to 2011; however, the use of e-cigarettes has increased nearly two-fold among middle and high school students. Moreover, the consumption of narghile and cigars also increased considerably from 2011 to 2012 [30]. In accordance with these studies, our results showed that $52.4 \%$ of smokers and ex-smokers had used narghile and $54.8 \%$ had used flavored cigarettes. In addition, $7 \%$ of smokers were exclusively using narghile.

The television, computer and mobile phone with internet access are the most highly used electronic media by adolescents; however, a computer with internet access is reportedly the media tool of choice for this age group. In addition, the students believe that knowledge about the harms of smoking could encourage cessation, and they desire more such knowledge. Three previous studies examined the effectiveness of smoking cessation programs for adolescents based on individualized counseling that was supplemented by internet programs [31-33]. One study that evaluated the cessation rate at the end of treatment and after three months of follow-up that included additional internet learning found that the immediate cessation rate was significantly higher in the group that used the internet in comparison to the group that did not use the internet tools [31]. The other two studies found no change in effectiveness in the group that 
used the complementary internet teaching, and it has been suggested that this result is possibly due to a lack of customized content $[32,33]$.

In summary, the results of the present study show that prevalence of cigarette smoking is stable at best; however, alternative forms of smoking are very popular and are considered less harmful by the users. Information about the consequences of all forms of tobacco smoking needs to be delivered in new and effective formats and should be tailored to reach this particular population.

The present study shows that despite large media campaigns, knowledge regarding the long-term consequences of tobacco smoke remains low and the use of alternative forms of smoking is high among adolescents. However, adolescents show interest in learning more, and the internet may be a useful tool to deliver information to this population in an attractive and persistent way.

\section{Acknowledgments}

André Luís Bertani received financial support from CAPES (Coordenação de Aperfeiçoamento de Pessoal de Nível Superior/ Brazil).

\section{References}

1. De Micheli D, Formigoni ML (2004) Drug use by Brazilian students: associations with family, psychosocial, health, demographic and behavioral characteristics. Addiction 99: 570-578.

2. Chassin L, Presson CC, Todd M, Rose JS, Sherman SJ (1998) Maternal socialization of adolescent smoking: the intergenerational transmission of parenting and smoking. Dev Psychol 34: 1189-1201.

3. Reichert J, Araújo AJ, Gonçalves CM, Godoy I, Chatkin JM, et al. (2008) Smoking cessation guidelines--2008. J Bras Pneumol 34: 845-880.

4. Sociedade Brasileira de Pneumologia e Tisiologia-SBPT (2011) Diretrizes Clinicas na Saúde Suplementar-Tabagismo. Rev Assoc Med Bras 18.

5. Sant'anna CC, De Araújo AJ, Orfaliais C (2004) Abordagens de grupos especiais: crianças e adolescentes. J Bras Pneumol 30: 8.

6. Farkas AJ, Gilpin EA, White MM, Pierce JP (2000) Association between household and workplace smoking restrictions and adolescent smoking. JAMA 284: 717-722.

7. Fitzgerald M, Poureslami I, Shum J (2014) Perception, Cultural Norm, and Self-Efficacy: Edges of Smoking Habit Triangle among Chinese Adult Smokers. J Community Med Health Educ 4: 5.

8. Barbosa Filho VC, Campos Wd, Lopes Ada S (2012) Prevalence of alcohol and tobacco use among Brazilian adolescents: a systematic review. Rev Saude Publica 46: 901-917.

9. Viegas CA (2008) Noncigarette forms of tobacco use. J Bras Pneumol 34: 1069-1073.

10. Knishkowy B, Amitai Y (2005) Water-pipe (narghile) smoking: an emerging health risk behavior. Pediatrics 116: e113-119.

11. West R, McNeill A, Raw M (2000) Smoking cessation guidelines for health professionals: an update. Health Education Authority. Thorax 55: 987-999.

12. Beaty T, Dornelles AC, Sahuque T, Urrego F (2013) Evaluation of pediatricians' adherence to tobacco prevention, control, and treatment guidelines before and after an educational outreach program. Ochsner J 13: 375-379.

13. Lopes GT, Belchior LC, Felipe ICV (2012) Dinâmicas de criatividade e sensibilidade na abordagem de álcool e fumo em adolescentes. Rev Enferm UFRJ 20: 6
14. Gomes MNC (2012) Percepção das consequências à saúde pelo consumo de drogas lícitas: um estudo com adolescentes.: Universidade Estadual da Paraíba.

15. Zeitoune RCG, Ferreira VS, Silveira HS (2012) O conhecimento de adolescentes sobre drogas lícitas e ilícitas: uma contribuição para a enfermagem comunitária. Esc Anna Nery 16: 7.

16. de Almeida AF, Mussi FC (2006) [Smoking: knowledge, attitudes, habits and degree of dependence of young adults in Salvador]. Rev Esc Enferm USP 40: 456-463.

17. Zigmond AS, Snaith RP (1983) The hospital anxiety and depression scale. Acta Psychiatr Scand 67: 361-370.

18. Heatherton TF, Kozlowski LT, Frecker RC, Fagerström KO (1991) The Fagerström Test for Nicotine Dependence: a revision of the Fagerström Tolerance Questionnaire. Br J Addict 86: 1119-1127.

19. DiClemente CC, Prochaska JO (1982) Self-change and therapy change of smoking behavior: a comparison of processes of change in cessation and maintenance. Addict Behav 7: 133-142.

20. Tavares BF, Béria JU, Silva de Lima M (2001) [Drug use prevalence and school performance among adolescents]. Rev Saude Publica 35: 150-158.

21. Instituto Brasileiro de Geografia e Estatística - IBGE. Pesquisa Nacional de Saúde do Escolar.

22. Malta DC, Iser BP, Sá NN, Yokota RT, Moura Ld, et al. (2013) [Trends in tobacco consumption from 2006 to 2011 in Brazilian capitals according to the VIGITEL survey]. Cad Saude Publica 29: 812-822.

23. Rodrigues MC, Viegas CA, Gomes EL, Morais JP, Zakir JC (2009) Prevalence of smoking and its association with the use of other drugs among students in the Federal District of Brasília, Brazil. J Bras Pneumol 35: 986-991.

24. Global Youth Tabacco Survey Collaborative Group (2002) Tobacco use among youth: a cross country comparison. Tob Control 11: 252-270.

25. Neto ASM, Cruz AA (2003) Tabagismo em amostra de adolescentes escolares de Salvador-Bahia. J Bras Pneumol 29: 9.

26. Kaleta D, KozieÅ, A, MiÅskiewicz P (2009) [MPOWER--strategy for fighting the global tobacco epidemic]. Med Pr 60: 145-149.

27. Rocha JBT, Salla LF, Figueira ACM (2009) Percepções acerca do fumo passivo: um olhar sobre o ensino de ciências e seu comprometimento na construção da cidadania para a saúde e qualidade de vida. Educação 34: 16.

28. Instituto Nacional do Câncer - INCA. Vigilância de Tabagismo em Escolares.

29. Smith-Simone S, Maziak W, Ward KD, Eissenberg T (2008) Waterpipe tobacco smoking: knowledge, attitudes, beliefs, and behavior in two U.S. samples. Nicotine Tob Res 10: 393-398.

30. Centers for Disease Control and Prevention (CDC) (2013) Tobacco product use among middle and high school students--United States, 2011 and 2012. MMWR Morb Mortal Wkly Rep 62: 893-897.

31. Mermelstein R, Turner L (2006) Web-based support as an adjunct to group-based smoking cessation for adolescents. Nicotine Tob Res 8 Suppl 1: S69-76.

32. Patten CA, Croghan IT, Meis TM, Decker PA, Pingree S, et al. (2006) Randomized clinical trial of an Internet-based versus brief office intervention for adolescent smoking cessation. Patient Educ Couns 64: 249-258.

33. Aveyard P, Cheng KK, Almond J, Sherratt E, Lancashire R, et al. (1999) Cluster randomised controlled trial of expert system based on the transtheoretical ("stages of change") model for smoking prevention and cessation in schools. BMJ 319: 948-953. 